\title{
ОТДЕЛЬНЫЕ АСПЕКТЫ СООТНОШЕНИЯ ПОНЯТИЙ «РЕЖИМ», «ПРАВОВОЙ РЕЖИМ» И «АДМИНИСТРАТИВНО-ПРАВОВОЙ РЕЖИМ»
}

\begin{abstract}
Аннотация: В статье автор анализирует соотношение понятий "режим» и «правовой режим», формулирует собственную позицию относительно способов исследования данной юридической категории, анализирует имеющиеся научные мнения относительно понятия и содержания правового режима.Автор использует свою систему исследования понятия и признаков правовых режимов - начиная от непосредственного определения "правовой режим» и "административно-правовой режим», которое включало бы в себя описательносодержательную характеристику данного правового явления, выявления и исследования признаков рассматриваемой категории, демонстрирующих все грани «правового режима» и "административно-правового режима» и заканчивая исследованием содержания и признаков понятий «правовой режим» и "административно-правовой режим» путем их сопоставления и сравнительного анализа с иными правовыми категориями. Методологическую основу статьи составили современные достижения теории познания. В процессе исследования применялись общефилософский, теоретический, общефилософские методы (диалектика, системный метод, анализ, синтез, аналогия, дедукция, наблюдение, моделирование), традиционно правовые методы (формально-логический), а также методы, используемые в конкретно-социологических исследованиях (статистические, экспертные оценки и др.). В статье приводятся имеющиеся в законодательстве и научных работах варианты использования понятий правового режима. Также в работе отмечается, что одним из фундаментальных понятий юридической науки является понятие «правового режима». Оно привлекает внимание и ученых, занимающихся исследованием общеправовых категорий юриспруденции и представителей отдельных отраслевых наук, в частности, административного права. В завершении статьи, подводя итог рассматриваемой теме, автор предлагает шесть наиболее типичных подходов к определению понятия «правовой режим».
\end{abstract}

Ключевые слова: режим, режимный, право, регулирование, воздействие, полиция, соотношение, чрезвычайное, положение, обеспечение.

Review: The author analyzes the correlation between the notions "regime" and "legal regime", formulates his own attitude towards the methods of study of this legal category, analyzes the existing scientific opinions about the notion and the essence of legal regime. The author uses his own system of stydy of the notion and the features of legal regimes - from the definition of "legal regime" and "administrative-legal regime", which would include the descriptive-substantive characteristic of this legal phenomenon, the revelation and research of the features of this category demonstrating all the sides of "legal regime" and "administrative-legal regime" to the study of the essence and the features of the notions "legal regime" and "administrative-legal regime" by means of their comparison and comparative analysis with other legal categories. The methodology of the research is based on the modern achievements of epistemology. The author uses the general philosophical and theoretical methods (dialectics, the system approach, analysis, synthesis, analogy, deduction, observation, modeling), the traditional legal methods (formal-logical), and the methods used in specific sociological research (the statistic method, expert assessments, etc.). The article describes the existing in legislation and in scientific works variants of use of legal regime definitions. The author notes that the notion "legal regime" is one of fundamental notions of legal science. It attracts the attention 
of scientists dealing with general legal categories of jurisprudence and administrative law. In the conclusion the author offers six typical approaches to the definition of the notion "legal regime".

Keywords: regime, regime, law, regulation, impact, police, correlation, emergency, state, provision.

$\mathrm{O}$ дним из фундаментальных понятий юридической науки является понятие «правового режима». Оно привлекает внимание и ученых, занимающихся исследованием общеправовых категорий юриспруденции и представителей отдельных отраслевых наук, в частности, административного права.

Понятие «правовой режим» активно используется как в юридической литературе, все более прочно утверждаясь в качестве одной из важнейших категорий правоведения, так и при конструировании правовых норм. В частности, в законодательстве мы встречаем такие упоминания правового режима, как «таможенный режим» ${ }^{1}$, «режим хозяйственной деятельности» ${ }^{2}$, «валютный режим» ${ }^{3}$, «режим чрезвычайного положения» ${ }^{4}$, «режим военного положения» ${ }^{5}$, «режим особой охраны» ${ }^{6}$, «режим секретности» ${ }^{7}$ «режим наиболь-

\footnotetext{
«Таможенный кодекс Таможенного союза» (приложение к Договору о Таможенном кодексе Таможенного союза, принятому Решением Межгосударственного Совета ЕврАзЭС на уровне глав государств от 27.11.2009 № 17) (ред. от 16.04.2010) // «Собрание законодательства РФ», 13.12.2010, № 50 , ст. 6615 .

2 Закон Санкт-Петербурга от 19.01.2009 № 820-7 (с изм. от 22.06.2012) «О границах зон охраны объектов культурного наследия на территории Санкт-Петербурга и режимах использования земель в границах указанных зон и о внесении изменений в Закон Санкт-Петербурга «О Генеральном плане Санкт-Петербурга и границах зон охраны объектов культурного наследия на территории Санкт-Петербурга» (принят ЗС СПб 24.12.2008) // «Информационный бюллетень Администрации Санкт-Петербурга», № 7/1, 04.03.2009.

3 «Статьи Соглашения Международного Валютного Фонда» (приняты 22.07.1944) (ред. от 15.12.2010).

4 Федеральный конституционный закон от 30.05.2001 № 3-ФКЗ (ред. от 07.03.2005) «О чрезвычайном положении» // «Собрание законодательства РФ», 04.06.2001, № 23, ст. 2277.

5 Федеральный конституционный закон от 30.01 .2002 № 1-ФКЗ (ред. от 28.12.2010) «О военном положении» // «Собрание законодательства РФ», 04.02.2002, № 5, ст. 375.

6 Федеральный закон от 14.03.1995 № 33-Ф3 (ред. от 28.12.2013) «Об особо охраняемых природных территориях» // «Собрание законодательства РФ», 20.03.1995, № 12, ст. 1024.

7 Федеральный закон от 21.07.2011 № 256-Ф3 (ред. от 02.07.2013) «О безопасности объектов топливно-энергетического комплекса» // «Собрание законодательства РФ», 25.07.2011, № 30 (ч. 1), ст. 4604.
}

шего благоприятствования» ${ }^{8}$ и т. п.

Наряду с многообразием законодательных конструкций, включающих в себя «правовые режимы», многие ученые используют данное понятие в структуре своих исследований по предметно-объектовому признаку. Так, в научных исследованиях мы встречаем «миграционно-правовой режим» ${ }^{9}$, «правовой режим зданий и сооружений» ${ }^{10}$, «правовой режим информации» ${ }^{11}$, «правовой режим оборота оружия и взрывчатых веществ» ${ }^{12}$, «режим обеспечения общественного порядка» ${ }^{13}$ и др.

Учитывая значительный научный материал, посвященный правовым режимам, многосторонность, а также многоаспектность данного явления, считаем целесообразным структурно рассмотреть данную категорию - от непосредственного буквального толкования, к общеправовым, общетеоретическим базисным характеристикам и, наконец, детальному отраслевому административноправовому исследованию.

Понимание сущности правовых и административно-правовых режимов возможно следующими способами:

1. Непосредственное определение «правовой режим» и «административно-правовой режим», которое включало бы в себя описательно-со-

8 Протокол от 16.12.2011 «О присоединении Российской Федерации к Марракешскому соглашению об учреждении Всемирной торговой организации от 15 апреля 1994 г.» (Протокол ратифицирован Федеральным законом от 21.07.2012 № 126-Ф3) // «Бюллетень международных договоров», № 12, декабрь, 2012.

9 Жеребцов А.Н. Миграционно-правовые режимы: теория и практика административно-правового регулирования: Монография. Волгоград: Издательство Волгоградского института экономики, социологии и права. 2009. 264 с.

10 Кузьмина И.Д. Правовой режим зданий и сооружений как объектов недвижимости. Дис. ... докт. юрид. наук. Томск, 2004. - 432 c.

11 Терещенко Л.К. Правовой режим информации. Дис. ... докт. юрид. наук. М., 2011. - 415 с.

12 Долгополов А.А. Теоретические аспекты формирования и реализации административно-правовых режимов оборота оружия и взрывчатых веществ // Очерки новейшей камералистики. - 2007. - №2. С. 6.

13 Аврутин Ю. Е. К вопросу об административно-правовом режиме обеспечения общественного порядка // Административное право и процесс. - 2013. - № 7. - С. 32-36. 
держательную характеристику данного правового явления.

2. Выявление и исследование признаков рассматриваемой категории, демонстрирующих все грани «правового режима» и «административно-правового режима».

3. Исследование содержания и признаков понятий «правовой режим» и «административноправовой режим» путем их сопоставления и сравнительного анализа с иными правовыми категориями.

На наш взгляд, правильное уяснение смысла данного правового института и его места и роли в правовой системе Российской Федерации возможно только при его комплексном исследовании по всем вышеуказанным направлениям.

Предметом методологического исследования административно-правовых режимов должны стать их понятие, признаки, особенности, содержание и структура.

Режим (в переводе с латинского regimen управление), термин, который имеет широкий спектр применения, и в рамках нашего исследования будут рассматриваться только отдельные его аспекты. В этой связи под режимом в целом, можно понимать:

1. Систему правил, мероприятий, необходимых для той или иной цели;

2. Условия работы, деятельности, существования чего-либо;

3. Определенное состояние, положение, статус кого-либо или чего-либо.

Ряд авторов, «режим» определяют в узком аспекте, посредством совокупности правил поведения, в широком - через всю систему мер, которые используются для достижения поставленных целей ${ }^{14}$.

Данная трактовка, по мнению В.Б. Рушайло, подчеркивает правоохранительный характер режима как явления, прежде всего, юридического, создающего условия, обеспечивающие заданное состояние объекта: «На наш взгляд, подобная точка зрения ближе всего к юридической цели функционирования режима как некой общности правоустановлений» ${ }^{15}$. Также, по мнению автора, данная трактовка режима приближает его к понятию правового режима, поскольку оно охватывает и правовой статус субъектов отношений, и мето-

14 Наташев А.Е., Стручков Н.А. Основы теории исправительно-трудового права. М., 1967. С. 93.

15 Рушайло В.Б. Административно-правовые режимы: Монография. М.: Щит-М, 2000. С. 12. ды, определяемые государством для поддержания установленных законом правоотношений.

Считаем целесообразным присоединиться к точке зрения П.В. Космыниной, и не в полной мере поддержать указанную позицию В.Б. Рушайло, поскольку в арсенале государства наряду с правовыми имеются и иные инструменты управления: прямое администрирование, финансовая поддержка и т.п. ${ }^{16}$

Наиболее показательной содержательной характеристикой в общефилософском понимании режима, является указание на наличие такого синонима слова «режим», как «порядок» ${ }^{17}$. В словаре В.И. Даля одно из пониманий режима - способ управления, совокупность административных мероприятий ${ }^{18}$. Отсюда вытекает одно из главных изначальных пониманий режимов, как некоего способа упорядочить те или иные процессы, в том числе и в сфере функционирования государства.

Зачастую, понимание термина «режим» ограничивается узкими рамками установления жесткого порядка в какой-либо сфере деятельности. С одной стороны - это не случайно. Ведь в повседневной жизни о режиме мы говорим тогда, когда возникают обстоятельства неординарного порядка и наши действия, в целях недопущения ошибок, ущерба или же достижения необходимого или наибольшего эффекта, нуждаются в строгой регламентации, когда наша деятельность связана с предметами, объектами, в силу своей специфики требующими индивидуального обращения ${ }^{19}$. C другой стороны, основной целью режимов является определенная упорядоченность общественных отношений, исходя из этого, наиболее жесткие режимные меры преследуют цель обезопасить граждан, общество и государство от более опасных нарушений и угроз.

Объективно наличие и функционирование административно-правовых режимов имело место намного ранее, чем его содержание и признаки стали предметом научных исследований даже в

\footnotetext{
16 Космынина П.В. Правовой режим предупреждения преступлений: Монография. - М.: ВНИИ МВД России, 2005. - С. 9.

17 Абрамов Н. Словарь русских синонимов и сходных по смыслу выражений. - 7-е изд., стереотип. - Москва: Русские словари, 1999. - С. 497.

18 Даль В.И. Толковый словарь живого великорусского языка: В 4 т. - Спб., 1863-1866.

19 Космынина П.В. Правовой режим предупреждения преступлений: Монография. - М.: ВНИИ МВД России, 2005. C. 24 .
} 
общеправовом смысле. Поэтому, можно говорить о наличии специфической характеристики режимов с точки зрения юридической науки - исследование их проводилось от частного к общему, то есть, изначально сформировавшись в отдельных отраслевых юридических группах и привлекая внимание ученых отдельных отраслей системы российского права, общеправовое и общетеоретическое исследование вопросов, связанных с правовыми режимами выступило необходимой научной составляющей, формирующей фундамент данной области правовых знаний. В связи с вышеизложенным, согласимся с профессором С.С.Алексеевым в том, что научные исследования, преследовавшие цель выяснить специфику юридического регулирования определенного участка деятельности, в особенности, когда эта деятельность имеет строго определенный объект, проводились под углом зрения правового режима данного объекта, вида деятельности $^{20}$. Когда же при изучении системы права выяснилось, что для каждой отрасли характерен свой специфический режим регулирования и в нем как раз концентрируется юридическое своеобразие отрасли, то стало очевидным, что рассматриваемое понятие выражает определяющие, узловые стороны правовой действительности. Вполне оправданно поэтому, что в литературе предпринимались попытки и общетеоретического осмысления этой категории. Причем исследование правовых режимов как общетеоретического явления, общепринято и традиционно. В частности, данная правовая категория является предметом научного осмысления таких теоретиков права как В.Б. Исаков, А.В. Малько, Н.И. Матузов, А.А. Мохов, С.С. Алексеев, О.С. Родионов, Э.Ф. Шамсумова и др.

В монографии «Правовой режим предупреждения преступлений» П.В. Космынина достаточно детально анализирует подход В.Б. Исакова относительно содержания понятия «правовой режим» и его производности от общей категории «социальный режим», нашедшей закрепление в правовых нормах и обеспеченный совокупностью юридических средств. Указанная формулировка, по мнению П.В. Космыниной, кажется неточной, поскольку возникает немало вопросов о значении термина «социальный режим». Автор, обращается к анализу научных взглядов советского времени на сущность и содержание права, его роли и места в жизни общества с позиций марксистско-ленинского учения и анализе правового регулирования как неотделимой части идеологии социалистического общества. На наш взгляд, подобный анализ представляет определенный научный интерес с точки зрения ретроспективного исследования многообразия подходов к содержанию правовых режимов, однако не в полной мере проецируется на современные научные и правовые реалии, отражающие основные теоретические подходы к содержанию и пониманию правовых режимов.

Исходя из вышеизложенного, анализ научных источников теоретико-правового характера позволяет выделить следующие подходы:

1. Правовой режим понимается как элемент юридического инструментария, соединяющий в единую конструкцию определенный комплекс правовых средств;

2. Правовой режим анализируется как составная часть системы права, которая наряду с предметом и методом правового регулирования отвечает за отграничение одной отрасли права от другой;

3. Правовой режим рассматривается как совокупность правовых и организационно-технических мер, используемых в сфере безопасности, представляющая собой юридико-организационный институт;

4. Правовой режим анализируется как результат регулятивного воздействия на общественные отношения системы юридических средств;

5. Правовой режим отождествляется с юридической формой социального режима;

6. Под правовым режимом понимается распорядок действия права, создающий конкретную степень благоприятности либо неблагоприятности для удовлетворения интересов субъектов права.

\section{Библиография:}

1. Болтанова Е. С. Правовой режим в земельном праве: теория вопроса // Вестник Томского государственного университета . 2008. №315.

2. Жеребцов А.Н. Миграционно-правовые режимы: теория и практика администра-тивно-правового регулирования: Монография. Волгоград: Издательство Волгоградского института экономики, социологии и права. 2009.

20 Алексеев С. С. Теория права.М.: Издательство БЕК, 1995. C. 242 . 
3. Кузьмина И.Д. Правовой режим зданий и сооружений как объектов недвижимости. Дис. ... д-ра. юрид. наук. Томск, 2004.

4. Терещенко Л.К. Правовой режим информации. Дис. ... д-ра. юрид. наук. М., 2011.-415 с.

5. Долгополов А.А. Теоретические аспекты формирования и реализации администра-тивно-правовых режимов оборота оружия и взрывчатых веществ // Очерки новейшей ка-мералистики. - 2007.-№2.

6. Аврутин Ю. Е. К вопросу об административно-правовом режиме обеспечения об-щественного порядка // Административное право и процесс. - 2013.-№

7. Наташев А.Е., Стручков Н.А. Основы теории исправительно-трудового права. М., 1967.

8. Рушайло В.Б. Административно-правовые режимы: Монография. М.: Щит-М, 2000.

9. Космынина П.В. Правовой режим предупреждения преступлений: Монография. - М.: ВНИИ МВД России, 2005.

10. Абрамов Н. Словарь русских синонимов и сходных по смыслу выражений. - 7-е изд., стереотип. - Москва: Русские словари, 1999.

11. Алексеев С. С. Теория права. М.: Издательство БЕК, 1995.

12. Шмидт Т.Н. Чрезвычайное право как особый комплексный правовой институт // Право и политика. - 2013. - C. 1250 - 1254. DOI: 10.7256/1811-9018.2013.10.9604.

13. Утяшов Э.К. Правовые режимы: понятие, признаки, структура, методы правового регулирования. // Право и политика. - 2014. - 2. - С. 252 - 259. DOI: 10.7256/1811-9018.2014.2.7303.

14. Рыльская М.А. Особенности реализации специальных административных режимов // Административное и муниципальное право. - 2012. - 3. - С. $44-52$.

15. Куракин А.В., Костенников М.В., Обыденов В.В. К вопросу о соотношении понятий «административный процесс» и «административная юрисдикция» в деятельности полиции // Полицейская деятельность. - 2014. - 2. - С. 179 - 190. DOI: 10.7256/2222-1964.2014.2.11172.

\section{References (transliterated):}

1. Boltanova E. S. Pravovoi rezhim v zemel'nom prave: teoriya voprosa // Vestnik Tomskogo gosudarstvennogo universiteta . 2008. №315.

2. Zherebtsov A.N. Migratsionno-pravovye rezhimy: teoriya i praktika administra-tivno-pravovogo regulirovaniya: Monografiya. Volgograd: Izdatel'stvo Volgogradskogo instituta ekonomiki, sotsiologii i prava. 2009.

3. Kuz'mina I.D. Pravovoi rezhim zdanii i sooruzhenii kak ob"ektov nedvizhimosti. Dis. ... d-ra. yurid. nauk. Tomsk, 2004.

4. Tereshchenko L.K. Pravovoi rezhim informatsii. Dis. ... d-ra. yurid. nauk. M., 2011.-415 c.

5. Dolgopolov A.A. Teoreticheskie aspekty formirovaniya i realizatsii administra-tivno-pravovykh rezhimov oborota oruzhiya i vzryvchatykh veshchestv // Ocherki noveishei ka-meralistiki. - 2007.-№2.

6. Avrutin Yu. E. K voprosu ob administrativno-pravovom rezhime obespecheniya ob-shchestvennogo poryadka // Administrativnoe pravo i protsess. - 2013.-№

7. Natashev A.E., Struchkov N.A. Osnovy teorii ispravitel'no-trudovogo prava. M., 1967.

8. Rushailo V.B. Administrativno-pravovye rezhimy: Monografiya. M.: Shchit-M, 2000.

9. Kosmynina P.V. Pravovoi rezhim preduprezhdeniya prestuplenii: Monografiya. - M.: VNII MVD Rossii, 2005.

10. Abramov N. Slovar' russkikh sinonimov i skhodnykh po smyslu vyrazhenii. - 7-e izd., stereotip. - Moskva: Russkie slovari, 1999.

11. Alekseev S. S. Teoriya prava. M.: Izdatel'stvo BEK, 1995.

12. Shmidt T.N. Chrezvychainoe pravo kak osobyi kompleksnyi pravovoi institut // Pravo i politika. - 2013. - 10. - C. 1250 1254. DOI: 10.7256/1811-9018.2013.10.9604.

13. Utyashov E.K. Pravovye rezhimy: ponyatie, priznaki, struktura, metody pravovogo regulirovaniya. // Pravo i politika. 2014. - 2. - C. 252 - 259. DOI: 10.7256/1811-9018.2014.2.7303.

14. Ryl'skaya M.A. Osobennosti realizatsii spetsial'nykh administrativnykh rezhimov // Administrativnoe i munitsipal'noe pravo. - 2012. - 3. - C. $44-52$.

15. Kurakin A.V., Kostennikov M.V., Obydenov V.V. K voprosu o sootnoshenii ponyatii «administrativnyi protsess» i «administrativnaya yurisdiktsiya» v deyatel'nosti politsii // Politseiskaya deyatel'nost'. - 2014. - 2. - C. 179 - 190. DOI: 10.7256/2222-1964.2014.2.11172. 